\title{
Targeting fatigue specific factors in rheumatic inflammatory diseases: A cognitive behavioural approach
}

\author{
Elin Fjerstad ${ }^{1}$, Torkil Berge ${ }^{2}$, Stale $\mathrm{Nymo}^{3}$ and Rikke Helene $\mathrm{Moe}^{4 *}$ \\ ${ }^{1}$ Clinical Health Psychology Service in Somatic Hospital, Department of Psychiatry, Diakonhjemmet Hospital, Oslo, Norway \\ ${ }^{2}$ Department of Psychiatry, Diakonhjemmet Hospital, Oslo, Norway \\ ${ }^{3}$ Department of Medicine, Nordlandssykehuset HF, Bodø, Norway \\ ${ }^{4}$ National Advisory Unit on Rehabilitation in Rheumatology (NKRR), Division of Rheumatology and Research, Diakonhjemmet Hospital, Oslo, Norway
}

\begin{abstract}
Objectives: Fatigue is common and debilitating in rheumatic inflammatory disease. The multifactorial, persistent, invisible, subjective and unpredictable nature of this problem challenge patients' beliefs in their ability to influence and manage the physical and mental symptoms of fatigue. The objective of this study was to evaluate a new, cognitive behavioural approach, addressing key factors in maintaining and exacerbating symptoms of fatigue.
\end{abstract}

Methods: The study is an observational longitudinal pilot study with observations at three time-points including patients with rheumatic inflammatory disease who had persistent fatigue, recruited from a rheumatology outpatient clinic. A cognitive behavioural approach was developed and applied. Levels of fatigue, pain, and depressive symptoms were measured at baseline, immediately after the intervention, and three months post intervention. ClinicalTrials.gov: NCT03216616. July 13, 2017.

Results: The study population included 40 participants with rheumatic inflammatory disease and persistent fatigue. Mean disease duration was 14 (11) years (SD), and mean age was 45 (10) years (SD). Repeated measure Analysis of variance showed statistically significant improvement in self-reported fatigue and depressive symptoms immediately after the intervention and at 3 months follow-up. There was no change in pain (Visual Analogue Scale) during follow-up.

Conclusions: The results indicate a promising beneficial effect of this pragmatic cognitive behavioural intervention targeting fatigue and depressive symptoms, sustained 3 months post treatment. The efficacy should be confirmed in a randomized controlled clinical trial.

\section{Introduction}

Fatigue is a common, disabling and difficult-to-manage problem in rheumatic inflammatory diseases (IA) [1-5] as well as in other chronic diseases [6,7]. Depending on populations studied and outcome measures used, $40-80 \%$ of people with IA report fatigue as an important symptom $[1,5,8]$. Fatigue is as a subjective sensation of generalized weariness, both physical and mental. In healthy individuals fatigue is temporary, whereas in people with rheumatic disease, fatigue can be continuous and persistent despite appropriate daily rest [9]. Fatiguerelated symptoms can be explained by multiple and complex pathways that vary within and between patients over time $[5,10,11]$. In addition to factors like pain $[2,3,12]$ inflammation [13] and sleep problems [14], physical inactivity, deconditioning, depression, dysfunctional illness beliefs, distress and low self-efficacy may contribute to fatigue [1,15-18].

Severe fatigue predicts low physical and mental health related quality of life, depression $[19,20]$ and greater healthcare utilization $[3,21]$. Studies on work participation in rheumatoid arthritis (RA) have identified fatigue as a key predictor for work-loss [21-23]. People with rheumatic disease report fatigue as a key issue that clinicians frequently overlook $[12,17,24]$. They often believe that they should accept fatigue as a consequence of their condition. Fatigue management strategies are often acquired through trial and error with little or no input from health professionals [25], and providers say they do not know how to treat fatigue in people with RA $[23,26]$. However, an increasing interest in fatigue has improved during the last decade based on work in OMERACT [27], recommendations to report fatigue in clinical trials [28], and incorporation of fatigue as an important domain in the rheumatoid arthritis and psoriatic arthritis impact of disease (RAID and PsAID) questionnaires [29].

Improved treatment strategies and reduced disease activity is not always sufficient to alleviate fatigue. Several studies including people with RA in remission, indicate that they continue reporting high levels of fatigue even when optimally medically treated [12,30-32]. A metaanalysis suggested that biologic therapies have only small-to-moderate effects on fatigue [4], and a recent path-analysis model showed that disease activity, pain and personality did not play a secondary role in the explanatory factors for fatigue in RA [33]. A systematic review detected biopsychosocial predictors of fatigue in RA amendable to behavioural change, and emphasized the importance of individually targeting these [11].

${ }^{*}$ Correspondence to: Rikke Helene Moe, National Advisory Unit on Rehabilitation in Rheumatology (NKRR), Division of Rheumatology and Research, Diakonhjemmet Hospital, P.O.Box 23, No-0319 Oslo, Norway, E-mail: rikmoe@gmail.com

Key words: fatigue, inflammatory arthritis, rheumatoid arthritis, rehabilitation, rheumatology, cognitive behavioural therapy, depression

Received: June 15, 2020; Accepted: June 22, 2020; Published: June 25, 2020 
There is increasing evidence for the beneficial effect of psychosocial interventions and physical activity in managing fatigue in people with RA [34,35], e.g. exercise [36-38], mindfulness [39], cognitive behavioural therapy and self-management [5,40-42]. However, fatigue has traditionally not been identified as a primary outcome, and there was little apparent consideration of fatigue mechanisms in the design of these interventions present at the development of the current study [34].

The aim of the current trial was to evaluate a newly developed cognitive behavioural intervention for persistent fatigue that would fit the patients and the format of the outpatient clinic that could be accessible to patients and health care workers online in order to facilitate follow-up and implementation across all three levels of health care. The intervention was developed in close collaboration with patient partners, with the aim of addressing behavioural, emotional, and cognitive reactions, as key factors in maintaining and exacerbating, or relieving mental and physical fatigue symptoms.

\section{Materials and methods}

Adults with inflammatory rheumatic diseases, such as rheumatoid arthritis (RA), ankylosing spondylitis (AS), systemic lupus erythematosus (SLE) and psoriatic arthritis (PsA), were recruited to this observational longitudinal pilot study from a specialized rheumatology outpatient clinic at Diakonhjemmet Hospital. They were all optimally medically treated for their diseases. Participants were included if they had persistent severe fatigue (more than one year reporting considerable fatigue [43]), and wanted to learn skills for coping with fatigue and managing daily activities. There were no exclusion criteria.

\section{Ethics, consent and permissions}

All participants gave their written consent, according to the declaration of Helsinki. The study was approved by The Regional Committee for Medical and Health Research Ethics, and registered in ClinicalTrials.gov: NCT03216616.

\section{Intervention}

The study team developed a cognitive behavioural intervention in close cooperation with patients, based on key elements from other manual-based cognitive behavioural interventions for fatigue and rheumatic disease [5,40] and multiple sclerosis [44], and years of clinical experience working with patients with rheumatic disease and other chronic diseases in a specialized hospital setting.

The intervention was provided face-to-face at the outpatient clinic (Table 1). The treatment manual used in this study including a self-management manual is currently freely accessible from an open website supported by the Norwegian health authorities (https://www. kognitiv.no/psykisk-helse/ulike-lidelser/utmattelse/). The clinical psychologists who took part in developing the manual also delivered the intervention.

The aim of the intervention was to change behavioural and cognitive factors related to the participant's symptoms and disability, with special emphasis on strengthening perceived self-efficacy in the management of fatigue, with the following interventions included:

Education about the biopsychosocial model of fatigue, teaching the participants to use the five areas model [45] to investigate the impact of bodily reactions, thoughts, feelings, behaviour and environmental factors in everyday situations.

Establishing a baseline of activity and rest, and learning a method for self-monitoring levels of fatigue on a scale from 1 to 10 .

Making an activity plan for improved well-being, a tool for changing unhelpful behaviour, and to develop a better balance between activity and rest.

Guiding participants to address unhelpful cognitions, including fears about symptoms and activity, e.g. by using reflective questions.

Using mental strategies for unhelpful and excessive worry and rumination.

Addressing social and emotional obstacles to improvement through problem solving.

Using homework and practice to implement mental and behavioural strategies in everyday life.

\section{Measures}

The participants reported levels of fatigue, pain, and depressive symptoms at three time-points; at baseline, after the intervention and three months after completing the intervention.

Table 1. Brief cognitive behavioural therapy intervention for fatigue management

\begin{tabular}{|c|c|c|c|}
\hline Session & Themes & Homework & Information booklet \\
\hline 1 & $\begin{array}{l}\text { Information about the course. How to understand fatigue? } \\
\text {-The biopsychosocial model } \\
\text { - The five areas model }\end{array}$ & $\begin{array}{l}\text { Read the booklet } \\
\text {-Use the five areas model and record body reactions, thoughts, } \\
\text { feelings and behaviour in two typical situations with fatigue }\end{array}$ & $\begin{array}{l}\text {-Biopsychosocial understanding of fatigue } \\
\text {-Summary }\end{array}$ \\
\hline 2 & $\begin{array}{l}\text { Balance and variation in daily activities } \\
\text {-Recording of daily activities (what, why, how and when) } \\
\text { - Patterns of activity (over-, under- } \\
\text { boom and bust) }\end{array}$ & $\begin{array}{l}\text { Read the booklet } \\
\text {-Record daily activities, rest, refreshing activities, and level of } \\
\text { fatigue during a week }\end{array}$ & $\begin{array}{l}\text {-Balance and variation in daily activities } \\
\text {-Summary }\end{array}$ \\
\hline 3 & $\begin{array}{l}\text { Balance and variation in daily activities } \\
\text {-Principles for composing a tailored } \\
\text {-Habits and how to change them: } \\
\text { Use of implementation intentions }\end{array}$ & Read the booklet -Make a tailored activity plan & $\begin{array}{l}\text {-Balance and variation in daily activities } \\
\text {-Summary }\end{array}$ \\
\hline 4 & $\begin{array}{l}\text { Mental strategies for management of fatigue } \\
\text {-The inner dialogue } \\
\text {-How to record inner dialog with the ABC-model } \\
\text { (Activation situation - Belief (thoughts) } \\
\text {-Consequences (fatigue, feelings, actions) }\end{array}$ & $\begin{array}{l}\text { Read the booklet } \\
\text {-Use the ABC-model }\end{array}$ & $\begin{array}{l}\text {-Mental strategies for management of fatigue } \\
\text {-Summary }\end{array}$ \\
\hline 5 & $\begin{array}{l}\text { Strategies for unhelpful and excessive worry and } \\
\text { rumination }\end{array}$ & $\begin{array}{l}\text { Read the booklet } \\
\text {-Record your typical patterns of rumination and worry during } \\
\text { two days }\end{array}$ & $\begin{array}{l}\text {-Excessive rumination and worry takes energy } \\
\text {-Summary }\end{array}$ \\
\hline 6 & $\begin{array}{l}\text { The way ahead } \\
\text {-What has been important for me, and } \\
\text { how to implement it in daily life? }\end{array}$ & & -Summary \\
\hline
\end{tabular}


The Chalder Fatigue Questionnaire (CFQ) is an 11-item questionnaire measuring the severity of physical and mental fatigue on two separate subscales [46]. Items 1-7 represent physical fatigue (e.g., lack energy, feel weak, less muscle strength, need to rest) and items 8-11 represents mental fatigue (e.g., concentration, memory). Response options are: "Less than usual," "No more than usual," "More than usual," and "Much more than usual". The ratings of items are added together to calculate the total score (0-33), and high scores represent greater levels of fatigue, where 29 of 33 discriminates clinically relevant from non-clinical relevant fatigue [47]. CFQ was developed to assess disabling fatigue severity in hospital and community populations, and was originally published in 1993 with further psychometric evaluation in 2010 [48]. CFQ has been reported to have good internal consistency in populations with chronic fatigue, and is considered sensitive to change in rheumatology [48]. The Norwegian version is available in Norwegian from the Norwegian Association for Cognitive Behavioural Therapy, but this version is to our knowledge not tested for psychometric properties.

Pain was rated on a visual analogue scale (VAS) [49,50], a $10 \mathrm{~cm}$ long line from no pain (0) to worst possible pain (10).

The PHQ-9 is a screening questionnaire [51] containing nine questions about the severity of depressive symptoms, with the following answer categories: "Not at all", "Various days", "More than half the days" and "Almost every day". Respectively zero, one, two or three points were scored, and a summed score of the nine questions was calculated. The questions relate to experiences over the previous two weeks. A score of 10 or more is considered a clinically relevant depression score of PHQ-9 [52]. The Norwegian version is tested for psychometric properties among adolescents with acceptable results [53].

\section{Statistical analysis}

Change in fatigue was analyzed using a repeated measure, analysis of variance. The data was normally distributed. Post hoc comparison of fatigue at time-point 1 and time-point 3 was analyzed with a paired sample t-test. A two-sided $\mathrm{p}$-value $<0.05$ was considered to be statistically significant. Statistical analyses were performed using STATA version 14.0 for Windows (Stata Corp LP, College Station, TX, USA) and SPSS version 21 for Windows (IBM Corp, Armonk, NY, USA).

\section{Results}

\section{Demographic characteristics}

A total of 40 participants, 36 women and 4 men, participated in the study (Table 2). Mean age (SD) was 45 (10) years and disease duration was 14 (11) years. Only five of the patients reported no other chronic diseases than inflammatory rheumatic disease, the rest had other co-morbid conditions in addition to their inflammatory rheumatic disease. Most participants had higher education.

\section{Changes over three time-points}

At baseline, participants reported high levels of fatigue and limited experience with being able to cope with it. They overall reported moderate levels of depressive symptoms, but had low baseline scores on sleep problems. Chalder Fatigue Questionnaire (symptoms of fatigue) and PHQ-9 (depression severity) showed statistically significant improvements from baseline to after the intervention, with values improving from Mean (SD) 13.89 (5.4) to 10.85 (4.9), and 25.13 (5.9) to 20.67 (6.8), respectively. These improvements remained statistically
Table 2. Baseline characteristics $(\mathrm{N}=40)$

\begin{tabular}{|l|l|}
\hline Variable & $\begin{array}{l}\text { N (\%), } \\
\text { or Mean (Standard Deviation, SD) }\end{array}$ \\
\hline Age & $44.85(10.43)$ years \\
\hline Gender & $36,90 \%(4,10 \%)$ women (men) \\
\hline Disease, N (\%) & $\begin{array}{l}\text { SpA: } 19(47.5 \%) \\
\text { RA: } 16(40 \%) \\
\text { Other: } 5(12.5 \%)\end{array}$ \\
\hline Disease duration & Mean $14.4($ SD 10.7$)$ years \\
\hline Education & $\begin{array}{l}\text { Primary: } 1(2.5 \%) \\
\text { Secondary: } 9(22.5 \%) \\
\text { Higher: } 30(75 \%)\end{array}$ \\
\hline Employment & Current payed work: $20(50 \%)$ \\
\hline \multirow{5}{*}{ Sleep problems } & $\begin{array}{l}\text { Never: } 3(7.5 \%) \\
\text { Occasionally: } 22(55 \%) \\
\text { Often: } 9(22.5 \%) \\
\text { Almost every night: } 6(15 \%)\end{array}$ \\
\hline As physical active as you wish & $\begin{array}{l}\text { Not at all: } 5(12.5 \%) \\
\text { To a small extent: } 12(30 \%) \\
\text { To some extent: } 17(42.5 \%) \\
\text { To a large extent: } 6(15 \%)\end{array}$ \\
\hline
\end{tabular}

RA=Rheumatoid Arthritis, $\mathrm{SpA}=$ Spondyloarthropathy

significant at follow-up three months after the intervention, to values Mean (SD) 9.46 (5.8), and 18.25 (7.1), respectively. There were no statistically significant changes in perceived level of VAS pain (Table 3).

\section{Discussion}

This cognitive behavioural intervention indicates statistically significant changes in self-reported levels of fatigue, self-perceived ability to cope with problems, and depressive symptoms. There were no statistically significant changes in self-reported levels of pain, sleep and physical activity over the three time-points, suggesting there are other factors mediating fatigue in this cohort of patients. The results suggest that people with rheumatic inflammatory disease with persistent fatigue, may benefit from the intervention by increasing the ability to cope with fatigue, and decrease self-reported fatigue and depressive symptoms. These promising results need to be confirmed in a randomized controlled clinical trial.

Another study reported that in addition to RA-related factors such as pain and inflammation, other factors like obesity, physical inactivity, sleep disturbances and depressive symptoms explain the majority of variations in fatigue, and that the most effective interventions address none RA-specific-factors [54]. The intervention in our study addressed fatigue specific factors such as the understanding of fatigue (illness perception) [55], and the behavioural patterns and cognitions involved in the vicious circles maintaining and exacerbating fatigue. This intervention did not specifically address problems with sleep, pain or physical activity. The decreased level of fatigue and depressive symptoms in this study could be due to changes in the way the participants deal with the symptoms, like behaviour change in an all-or-nothing activity pattern and a better balance between activity and rest. Insomnia is a known contributing factor to fatigue [14]. The participants in our study reported unexpectedly little sleep disturbances at baseline. The mechanisms involved in the high levels of fatigue in our sample could thus not primarily be due to sleep problems.

Depressive symptoms are one of the most consistent predictors of fatigue in RA [20], and the patients themselves often view depressive symptoms as a consequence, not a cause of fatigue [56]. The participants in our study reported moderate depressive symptoms at baseline. Following the intervention, the level of depressive symptoms improved from moderate to mild, and the participants reported an increased 
Table 3. Repeated measure ANOVA analyses: Changes over three time-points

\begin{tabular}{|c|c|c|c|c|c|}
\hline Scale & T1 Mean (SD) & T2 Mean (SD) & T3 Mean (SD) & $\begin{array}{c}\text { ANOVA } \\
\text { Diff. }\end{array}$ & Paired t-test T1-3 \\
\hline Chalder fatigue \$ & $13.89(5.4)$ & $10.85(4.9)$ & $9.46(5.8)$ & $p<0.001$ & Diff 4.57 (CI: 2.2-7.0) \\
\hline PHQ-9\# & $25.13(5.9)$ & $20.67(6.8)$ & $18.25(7.1)$ & $p<0.001$ & Diff $6.44(\mathrm{CI}: 4.0-8.9)$ \\
\hline VAS pain & $45.54(24.4)$ & $39.08(21.1)$ & $36.9(23.0)$ & $p=0.241$ & $38,33,28$ \\
\hline
\end{tabular}

$\$$ Chalder Fatigue Questionnaire (0-39 last 2 weeks); \# PHQ-9 depression score (0-70, last 7 days), scored on a $0-3$ scale where $0=$ not difficult to $3=$ extremely difficult; $a$ VAS pain $(0-100$, where 0 is no pain and 100 worst possible pain); $\mathrm{N}=$ number of participants

sense of value and a more positive and supporting attitude towards themselves. By understanding fatigue as a multifactorial symptom, it becomes possible to detect areas for self-management; windows of opportunities. The patient may not be able to influence disease activity directly, but to a certain degree they are able to control how they think, feel and behave in relation to the symptoms of fatigue. They can thus strengthen their experience of self-efficacy in managing fatigue and everyday tasks and decrease feelings of hopelessness and depressive symptoms.

In this study, fatigue was a specific criterion for inclusion, and a substantial problem for the included participants. There was a low rate of attrition, suggesting commitment and motivation for selfmanagement of fatigue. This was also visible in a recent randomized control trial with a comparable cognitive behavioural intervention for people with fatigue and RA in UK, that showed positive effects on fatigue sustained at 2 years follow-up, as compared to a booklet [42]. The programme included people with RA and was given by health professionals, as in this study people with IA were included, and the intervention was given by psychologists. A major treatment challenge for fatigue in IA lies in identifying interventions that are both effective and feasible for wide-spread dissemination [36]. Fatigue is a transdiagnostic symptom that may be similar across different disease groups, which offers an opportunity for generic treatment approaches (60) that, taken into account that factors driving fatigue vary, can be individually tailored [11]. We also believe interventions could be specifically tailored to fatigue-related symptoms. In psycho-oncologic interventions on emotional distress and quality of life, effect sizes are substantially larger when cancer survivors are selected on the basis of a threshold of the outcome variable, i.e. fatigue, insomnia or pain, than when participants are included regardless of their baseline standing [57]. Even though there are different biopsychosocial pathways to fatigue, the main challenge for people with fatigue is the same, to cope with the symptoms in their everyday life.

This opens up the possibility for self-management interventions for fatigue, in the form of an accessible and attractive widespread public health program, available to a great number of people in need of help. This implies increasing the size, reach or impact of the interventions [58]. We therefore developed an intervention manual, based on this study, and self-management materials to be used in collaboration with a health professional, e.g. a general practitioner, freely available online supported by the Norwegian health authorities (https://www.kognitiv. no/psykisk-helse/ulike-lidelser/utmattelse/) in order to facilitate follow-up, and implementation across all three levels of health care.

There are several limitations in this study, especially the small sample size and the absence of a control group, that limits the ability to draw any firm conclusions from our findings. Both pharmacological and non-pharmacological treatment is recommended in the treatment of inflammatory rheumatic disease. For those in remission, and in cases where fatigue cannot be explained by disease-related factors, there is a need for interventions that target psychosocial factors of fatigue.
This study provides promising information about beneficial effects of a cognitive behavioural intervention targeting persistent fatigue in people with rheumatic inflammatory disease. The benefits were sustained after 3 months. Efficacy should be confirmed by a randomized controlled clinical trial.

\section{Authors' contributions}

All authors were involved in developing the study design and analysed the data. Elin Fjerstad and Torkil Berge collected the data and wrote the first draft of the article. All authors read and provided feedback on the draft versions of the article and approved the final version.

\section{Ethics approval and consent to participate}

The study was approved by The Regional Committee for Medical and Health Research Ethics. All participants gave written consent in accordance with the declaration of Helsinki.

\section{Consent for publication}

All participants gave written consent to publish the study results.

\section{Acknowledgements}

We would like to thank all the participants in the study, the project group including Tore K. Kvien, Heidi Zangi, patient partner Thalita Blanck, Nina Lang and Ingrid Hyldmo.

\section{Declaration of interests}

All authors declare they have no conflicts of interest.

\section{Funding}

This project has been made possible by a grant from the Norwegian Dam Foundation.

\section{References}

1. Overman CL, Kool MB, Da Silva JA, Geenen R (2016) The prevalence of severe fatigue in rheumatic diseases: an international study. Clin Rheumatol 35: 409-415.

2. Nikolaus S, Bode C, Taal E, van de Laar MA (2013) Fatigue and factors related to fatigue in rheumatoid arthritis: a systematic review. Arthritis Care Res (Hoboken) 65: 1128-1146.

3. Pollard LC, Choy EH, Gonzalez J, Khoshaba B, Scott DL (2006) Fatigue in rheumatoid arthritis reflects pain, not disease activity. Rheumatology 45: 885-889.

4. Chauffier K, Salliot C, Berenbaum F, Sellam J (2012) Effect of biotherapies on fatigue in rheumatoid arthritis: a systematic review of the literature and meta-analysis. Rheumatology 51: 60-68.

5. Hewlett S, Chalder T, Choy E, Cramp F, Davis B, Dures E, et al. (2011) Fatigue in rheumatoid arthritis: time for a conceptual model. Rheumatology 50: 1004-1006.

6. Jelsness-Jorgensen LP, Bernklev T, Henriksen M, Torp R, Moum BA (2011) Chronic fatigue is associated with impaired health-related quality of life in inflammatory bowel disease. Aliment Pharmacol Ther 33: 06-14.

7. Bower JE (2014) Cancer-related fatigue--mechanisms, risk factors, and treatments. Nat Rev Clin Oncol 11: 597-609. 
8. Pilgaard T, Hagelund L, Stallknecht SE, Jensen HH, Esbensen BA (2019) Severity of fatigue in people with rheumatoid arthritis, psoriatic arthritis and spondyloarthritis Results of a cross-sectional study. PLoS One 14: e 0218831.

9. Davies H, Brophy S, Dennis M, Cooksey R, Irvine E, et al. (2013) Patient perspectives of managing fatigue in Ankylosing Spondylitis, and views on potential interventions: a qualitative study. BMC Musculoskelet Disord 14: 163.

10. Hewlett S, Ambler N, Almeida C, Cliss A, Hammond A, et al. (2011) Self-management of fatigue in rheumatoid arthritis: a randomised controlled trial of group cognitivebehavioural therapy. Ann Rheum Dis 70: 1060-1067.

11. Geenen R, Dures E (2019) A biopsychosocial network model of fatigue in rheumatoid arthritis: a systematic review. Rheumatology 58: v10-v21.

12. Madsen SG, Danneskiold-Samsoe B, Stockmarr A, Bartels EM (2016) Correlations between fatigue and disease duration, disease activity, and pain in patients with rheumatoid arthritis: a systematic review. Scand J Rheumatol 45: 255-261.

13. Norheim KB, Jonsson G, Omdal R (2011) Biological mechanisms of chronic fatigue. Rheumatology 50: 1009-1018.

14. Irwin MR, Olmstead R, Carrillo C, Sadeghi N, Fitzgerald JD, et al. (2012) Sleep loss exacerbates fatigue, depression, and pain in rheumatoid arthritis. Sleep 35: 537-543.

15. Hewlett S, Nicklin J, Treharne G (2008) Fatigue in musculoskeletal conditions. Topical Reviews: Reports on the Rheumatic Diseases Series.

16. Matcham F, Ali S, Hotopf M, Chalder T (2015) Psychological correlates of fatigue in rheumatoid arthritis: a systematic review. Clin Psychol Rev 39: 16-29.

17. Treharne GJ, Lyons AC, Hale ED, Goodchild CE, Booth DA, et al., (2008) Predictors of fatigue over 1 year among people with rheumatoid arthritis. Psychol Health Med 13: 494-504.

18. Katz P, Margaretten M, Trupin L, Schmajuk G, Yazdany J, et al. (2015) Sleep disturbance, depression, obesity, and physical inactivity explain a significant portion of fatigue in rheumatoid arthritis. Arthritis Care Res (Hoboken).

19. Breedveld FC, Han C, Bala M, van der Heijde D, Baker D, et al. (2005) Association between baseline radiographic damage and improvement in physical function after treatment of patients with rheumatoid arthritis. Ann Rheum Dis 64: 52-55.

20. Wolfe F, Michaud K (2009) Predicting depression in rheumatoid arthritis: the signal importance of pain extent and fatigue, and comorbidity. Arthritis Rheum 61: 667-673.

21. Feldthusen C, Bjork M, Forsblad-d'Elia H, Mannerkorpi K (2013) Perception, consequences, communication, and strategies for handling fatigue in persons with rheumatoid arthritis of working age--a focus group study. Clin Rheumatol 32: 557-566.

22. Lacaille D, White MA, Backman CL, Gignac MA (2007) Problems faced at work due to inflammatory arthritis: new insights gained from understanding patients' perspective. Arthritis Rheum 57: 1269-1279.

23. Primdahl J, Hegelund A, Lorenzen AG, Loeppenthin K, Dures E, et al. (2019) The Experience of people with rheumatoid arthritis living with fatigue: a qualitative metasynthesis. BMJ Open 9: e024338.

24. Repping-Wuts H, Uitterhoeve R, van Riel P, van Achterberg T (2008) Fatigue as experienced by patients with rheumatoid arthritis (RA): a qualitative study. Int J Nurs Stud 45: 995-1002.

25. O'Riordan R, Doran M, Connolly D (2017) Fatigue and Activity Management Education for Individuals with Systemic Lupus Erythematosus. Occup Ther Int 2017: 4530104.

26. Repping-Wuts H, van Riel P, van Achterberg T (2008) Rheumatologists' knowledge, attitude and current management of fatigue in patients with rheumatoid arthritis (RA). Clin Rheumatol 27: 1549-1555.

27. Kirwan JR, Hewlett SE, Heiberg T, Hughes RA, Carr M, et al. (2005) Incorporating the patient perspective into outcome assessment in rheumatoid arthritis--progress at OMERACT 7. J Rheumatol 32: 2250-2256.

28. Aletaha D, Landewe R, Karonitsch T, Bathon J, Boers M, et al. (2008) Reporting disease activity in clinical trials of patients with rheumatoid arthritis: EULAR/ACR collaborative recommendations. Arthritis Rheum 59: 1371-1377.

29. Gossec L, Paternotte S, Aanerud GJ, Balanescu A, Boumpas DT, et al. (2011) Finalisation and validation of the rheumatoid arthritis impact of disease score, a patientderived composite measure of impact of rheumatoid arthritis: a EULAR initiative. Ann Rheum Dis 70: 935-942.

30. Druce KL, Bhattacharya Y, Jones GT, Macfarlane GJ, Basu N (2016) Most patients who reach disease remission following anti-TNF therapy continue to report fatigue: results from the British Society for Rheumatology Biologics Register for Rheumatoid Arthritis. Rheumatology 55: 1786-1790.
31. Olsen CL, Lie E, Kvien TK, Zangi HA (2016) Predictors of Fatigue in Rheumatoid Arthritis Patients in Remission or in a Low Disease Activity State. Arthritis Care Res 68: 1043-1048.

32. van Steenbergen HW, Tsonaka R, Huizinga TW, Boonen A, van der Helm-van Mil AH (2015) Fatigue in rheumatoid arthritis; a persistent problem: a large longitudinal study. RMD Open 1: e000041.

33. Silva CFR, Duarte C, Ferreira RJO, Santos E, da Silva JAP (2020) Depression, disability and sleep disturbance are the main explanatory factors of fatigue in rheumatoid arthritis: a path analysis model. Clin Exp Rheumatol 38: 314-321.

34. Cramp F, Hewlett S, Almeida C, Kirwan JR, Choy EH, et al. (2013) Nonpharmacological interventions for fatigue in rheumatoid arthritis. Cochrane Database Syst Rev 8: Cd008322.

35. Prothero L, Barley E, Galloway J, Georgopoulou S, Sturt J (2018) The evidence base for psychological interventions for rheumatoid arthritis: A systematic review of reviews. Int J Nurs Stud 82: 20-29.

36. Katz P (2017) Causes and consequences of fatigue in rheumatoid arthritis. Curr Opin Rheumatol 29: 269-276.

37. Katz P, Margaretten M, Gregorich S, Trupin L (2018) Physical Activity to Reduce Fatigue in Rheumatoid Arthritis: A Randomized Controlled Trial. Arthritis Care Res 70: $1-10$

38. Rongen-van Dartel SA, Repping-Wuts H, Flendrie M, Bleijenberg G, Metsios GS, et al. (2015) The effect of aerobic exercise training on fatigue in rheumatoid arthritis: a meta-analysis. Arthritis Care Res 67: 1054-1062.

39. Zangi HA, Mowinckel P, Finset A, Eriksson LR, Hoystad TO, et al. (2012) A mindfulness-based group intervention to reduce psychological distress and fatigue in patients with inflammatory rheumatic joint diseases: a randomised controlled trial. Ann Rheum Dis 71: 911-917.

40. Evers AW, Kraaimaat FW, van Riel PL, de Jong AJ (2002) Tailored cognitivebehavioral therapy in early rheumatoid arthritis for patients at risk: a randomized controlled trial. Pain 100: 141-153.

41. Hewlett S, Almeida C, Ambler N, Blair PS, Choy E, et al. (2019) Group cognitivebehavioural programme to reduce the impact of rheumatoid arthritis fatigue: the RAFT RCT with economic and qualitative evaluations. Health Technol Assess 23: 1-130.

42. Hewlett S, Almeida C, Ambler N, Blair PS, Choy EH, et al. (2019) Reducing arthritis fatigue impact: two-year randomised controlled trial of cognitive behavioural approaches by rheumatology teams (RAFT). Ann Rheum Dis 78: 465-472.

43. Repping-Wuts H, Fransen J, van Achterberg T, Bleijenberg G, van Riel P (2007) Persistent severe fatigue in patients with rheumatoid arthritis. J Clin Nurs 16: 377-383.

44. van Kessel K, Moss-Morris R, Willoughby E, Chalder T, Johnson MH, et al. (2008) A randomized controlled trial of cognitive behavior therapy for multiple sclerosis fatigue. Psychosom Med 70: 205-213.

45. Greenberger DPC (2015) Mind over mood: A cognitive therapy treatment manual for clients. New York: The Guilford Press; 1st edition (March 15, 1995).

46. Chalder T, Berelowitz G, Pawlikowska T, Watts L, Wessely S, et al. (1993) Development of a fatigue scale. J Psychosom Res 37: 147-153.

47. Cella M, Chalder T (2010) Measuring fatigue in clinical and community settings. $J$ Psychosom Res 69: 17-22.

48. Hewlett S, Dures E, Almeida C (2011) Measures of fatigue: Bristol Rheumatoid Arthritis Fatigue Multi-Dimensional Questionnaire (BRAF MDQ), Bristol Rheumatoid Arthritis Fatigue Numerical Rating Scales (BRAF NRS) for severity, effect, and coping, Chalder Fatigue Questionnaire (CFQ), Checklist Individual Strength (CIS20R and CIS8R), Fatigue Severity Scale (FSS), Functional Assessment Chronic Illness Therapy (Fatigue) (FACIT-F), Multi-Dimensional Assessment of Fatigue (MAF), Multi-Dimensional Fatigue Inventory (MFI), Pediatric Quality Of Life (PedsQL) MultiDimensional Fatigue Scale, Profile of Fatigue (ProF), Short Form 36 Vitality Subscale (SF36 VT), and Visual Analog Scales (VAS). Arthritis Care Res 63: S263-286.

49. Flaherty SA (1996) Pain measurement tools for clinical practice and research. Aana J 64: 133-140.

50. Lee VC RJ (1996) Quality of Life and Pharmaeconomics in Clinical Trials: Defining Quality of Life in Chronic Pain Philadelphia: Lippincott-Raven Publishers.

51. Kroenke K, Spitzer RL, Williams JB (2001) The PHQ-9: validity of a brief depression severity measure. J Gen Intern Med 16: 606-613.

52. Kroenke K, Spitzer RL, Williams JB (2003) The Patient Health Questionnaire-2 validity of a two-item depression screener. Med Care 41: 1284-1292. 
53. Burdzovic Andreas J, Brunborg GS (2017) Depressive Symptomatology among Norwegian Adolescent Boys and Girls: The Patient Health Questionnaire-9 (PHQ-9) Psychometric Properties and Correlates. Front Psychol 8: 887.

54. Katz P, Margaretten M, Trupin L, Schmajuk G, Yazdany J, et al. (2016) Role of Sleep Disturbance, Depression, Obesity, and Physical Inactivity in Fatigue in Rheumatoid Arthritis. Arthritis Care Res 68: 81-90.

55. Lochting I, Fjerstad E, Garratt AM (2013) Illness perceptions in patients receiving rheumatology rehabilitation: association with health and outcomes at 12 months. BMC Musculoskelet Disord 14: 28.
56. Feldthusen C, Grimby-Ekman A, Forsblad-d'Elia H, Jacobsson L, Mannerkorpi K (2016) Explanatory factors and predictors of fatigue in persons with rheumatoid arthritis: A longitudinal study. J Rehabil Med 48: 469-476.

57. Faller H, Schuler M, Richard M, Heckl U, Weis J, et al. (2013) Effects of psychooncologic interventions on emotional distress and quality of life in adult patients with cancer: systematic review and meta-analysis. J Clin Oncol 31: 782-793.

58. Milat AJ, King L, Bauman A, Redman S (2011) Scaling up health promotion interventions: an emerging concept in implementation science. Health Promot J Austr 22: 238 .

Copyright: (C2020 Fjerstad E. This is an open-access article distributed under the terms of the Creative Commons Attribution License, which permits unrestricted use, distribution, and reproduction in any medium, provided the original author and source are credited. 